ADVANCES IN INTELLIGENT AND SOFT COMPUTING 73

Emilio Corchado

Paulo Novais

Cesar Analide

Javier Sedano (Eds.)

\title{
Soft Computing Models in Industrial and Environmental Applications, 5th International Workshop (SOCO 2010)
}

Springer 


\section{Editors}

Emilio Corchado

Departamento de Informática

y Automática

Facultad de Ciencias

Universidad de Salamanca

Plaza de la Merced S/N

37008, Salamanca

Spain

E-mail: escorchado@usal.es

Paulo Novais

Universidade do Minho

Departamento de Informática

Campus de Gualtar

4710-057 Braga

Portugal

E-mail: pjon@di.uminho.pt
Cesar Analide

Universidade do Minho

Departamento de Informática

Campus de Gualtar

4710-057 Braga

Portugal

E-mail: analide@di.uminho.pt

ISBN 978-3-642-13160-8

e-ISBN 978-3-642-13161-5

DOI 10.1007/978-3-642-13161-5

Advances in Intelligent and Soft Computing

ISSN 1867-5662

Library of Congress Control Number: 2010927160

(c) 2010 Springer-Verlag Berlin Heidelberg

This work is subject to copyright. All rights are reserved, whether the whole or part of the material is concerned, specifically the rights of translation, reprinting, reuse of illustrations, recitation, broadcasting, reproduction on microfilm or in any other way, and storage in data banks. Duplication of this publication or parts thereof is permitted only under the provisions of the German Copyright Law of September 9, 1965 , in its current version, and permission for use must always be obtained from Springer. Violations are liable for prosecution under the German Copyright Law.

The use of general descriptive names, registered names, trademarks, etc. in this publication does not imply, even in the absence of a specific statement, that such names are exempt from the relevant protective laws and regulations and therefore free for general use.

Typeset \& Cover Design: Scientific Publishing Services Pvt. Ltd., Chennai, India.

Printed on acid-free paper

543210

springer.com 


\section{Contents}

Agents and Multiagent Systems

A Security Proposal Based on a Real Time Agent to Protect Web Services Against DoS Attack .............. 1 Cristian Pinzón, Angélica González, Manuel Rubio, Javier Bajo

Approaching Real-Time Intrusion Detection through MOVICAB-IDS

Martí Navarro, Álvaro Herrero, Emilio Corchado, Vicente Julián

Hybrid Dynamic Planning Mechanism for Virtual

Organizations .

Sara Rodríguez, Vivian F. López, Javier Bajo

Combinatorial Auctions for Coordination and Control of Manufacturing MAS: Updating Prices Methods

Juan José Lavios Villahoz, Ricardo del Olmo Martínez, Alberto Arauzo Arauzo

\section{Intelligent Systems}

A Software Tool for Harmonic Distortion Simulation Caused by Non-linear Household Loads . . . . . . . . . . . . . . . 31 J. Baptista, R. Morais, A. Valente, S. Soares, J. Bulas-Cruz, M.J.C.S. Reis

A Multiobjective Variable Neighborhood Search for Solving the Motif Discovery Problem David L. González-Álvarez, Miguel A. Vega-Rodríguez, Juan A. Gómez-Pulido, Juan M. Sánchez-Pérez 
Solving the Routing and Wavelength Assignment Problem in WDM Networks by Using a Multiobjective Variable Neighborhood Search Algorithm .................

Álvaro Rubio-Largo, Miguel A. Vega-Rodríguez, Juan A. Gómez-Pulido, Juan M. Sánchez-Pérez

iGenda: An Event Scheduler for Common Users and

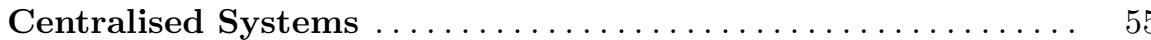

Ângelo Costa, Juan L. Laredo, Paulo Novais, Juan M. Corchado, José Neves

Scalable Intelligence and Adaptation in Scheduling DSS 63 Ana Almeida, Constantino Martins, Luiz Faria

\section{Evolutionary Computing}

A Parallel Cooperative Evolutionary Strategy for Solving the Reporting Cells Problem ...................

Álvaro Rubio-Largo, David L. González-Álvarez, Miguel A. Vega-Rodríguez, Sónia M. Almeida-Luz, Juan A. Gómez-Pulido, Juan M. Sánchez-Pérez

Optimization of Parallel Manipulators Using Evolutionary

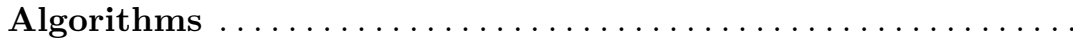

Manuel R. Barbosa, E.J. Solteiro Pires, António M. Lopes

Multi-criteria Manipulator Trajectory Optimization Based on Evolutionary Algorithms

E.J. Solteiro Pires, P.B. de Moura Oliveira, J.A. Tenreiro Machado

Combining Heuristics Backtracking and Genetic Algorithm to Solve the Container Loading Problem with Weight

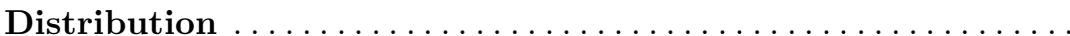

Luiz Jonatã Pires de Araújo, Plácido Pinheiro

A Decision Support System for Logistics Operations María D. R-Moreno, David Camacho, David F. Barrero, Miguel Gutierrez

\section{Energy and Environmental Applications}

Greenhouse Heat Load Prediction Using a Support Vector Regression Model. . . . . . . . . . . . . . . . . . . . . . . . . João Paulo Coelho, José Boaventura Cunha, Paulo de Moura Oliveira, Eduardo Solteiro Pires 
Evaluating the Low Quality Measurements in Lighting Control Systems ............................. 119

Jose R. Villar, Enrique de la Cal, Javier Sedano, Marco García

Soft Computing Models for an Environmental Application . . 127 Ángel Arroyo, Emilio Corchado, Verónica Tricio

\section{Hybrid Systems}

GRASP Algorithm for Optimization of Grids for Multiple

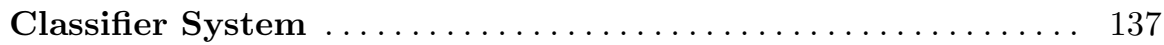
Tomasz Kacprzak, Krzysztof Walkowiak, Michat Woźniak

A Scatter Search Based Approach to Solve the Reporting Cells Problem

Sónia M. Almeida-Luz, Miguel A. Vega-Rodríguez, Juan A. Gómez-Pulido, Juan M. Sánchez-Pérez

Fuzzy Optimization of Start-Up Operations for Combined Cycle Power Plants . . . . . . . . . . . . . . . . . . . . . . . 153 Ilaria Bertini, Alessandro Pannicelli, Stefano Pizzuti

Catalog Segmentation by Implementing Fuzzy Clustering and Mathematical Programming Model 161 Amir Hassan Zadeh, Hamed Maleki, Kamran Kianfar, Mehdi Fathi, Mohammad Saeed Zaeri

Multi-Network-Feedback-Error-Learning with Automatic

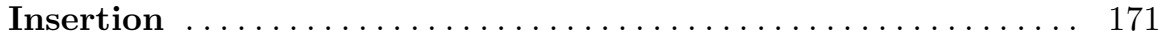
Paulo Rogério de Almeida Ribeiro, Areolino de Almeida Neto, Alexandre César Muniz de Oliveira

\section{Applications}

An Optimized 3D Surface Reconstruction Method Using Spatial Kalman Filtering of Projected Line Patterns . . . . . . . 179 An-Qi Shen, Ping Jiang

Decision Making and Quality-of-Information . . . . . . . . . 187 Paulo Novais, Maria Salazar, Jorge Ribeiro, Cesar Analide, José Neves

The Gene Expression Programming Applied to Demand

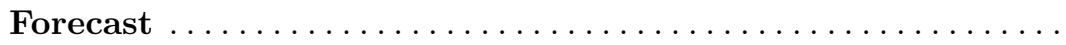


Brain Magnetic Resonance Spectroscopy Classifiers . . . . . . . 201

Susana Oliveira, Jaime Rocha, Victor Alves

A Bio-inspired Ensemble Model for Food Industry

Applications ..................................... 209

Bruno Baruque, Emilio Corchado, Jordi Rovira

\section{Hybrid Intelligent Systems and Applications}

Implementation of a New Hybrid Methodology for Fault Signal Classification Using Short -Time Fourier Transform and Support Vector Machines .................... 219 Tribeni Prasad Banerjee, Swagatam Das, Joydeb Roychoudhury, Ajith Abraham

Advances in Clustering Search .

Tarcisio Souza Costa, Alexandre César Muniz de Oliveira, Luiz Antonio Nogueira Lorena

WSAN QoS Driven Control Model for Building

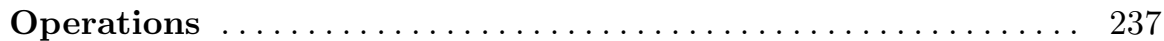
Alie El-Din Mady, Menouer Boubekeur, Gregory Provan

Intelligent Hybrid Control Model for Lighting Systems Using Constraint-Based Optimisation .

Alie El-Din Mady, Menouer Boubekeur, Gregory Provan, Conor Ryan, Kenneth N. Brown

Author Index 


\title{
A Security Proposal Based on a Real Time Agent to Protect Web Services Against DoS Attack
}

\author{
Cristian Pinzón, Angélica González, Manuel Rubio, and Javier Bajo
}

\begin{abstract}
This paper describes a novel proposal based on a real time agent to detect and block denial of service attacks within web services environments. The real time agent incorporates a classification mechanism based on a Case-Base Reasoning (CBR) model, where the different CBR phases are time bounded. In addition, the reuse phase of the CBR cycle incorporates a mixture of experts to choose a specific technique of classification depending on the feature of the attack and the available time to solve the classification.
\end{abstract}

Keywords: Multi-agent System, CBR, Web Service, SOAP Message, DoS attacks.

\section{Introduction}

New security issues as well as new ways of exploiting inherited old security threats can become a serious problem to applications based on web services. One of the threats that is becoming more common within web services environments and jeopardizes the availability factor is denial of service attack (DoS) [6] [5]. Since web services are a combination of a variety of technologies such as SOAP, HTTP, and XML, they are vulnerable to different type of attacks. For example, an attacker sends a malicious request (XML message) to the web service and the XML message forces the XML parser into an infinite recursion exhausting all

Cristian Pinzón

Universidad Tecnológica de Panamá, Av. Manuel Espinosa Batista, Panamá

e-mail: cristian_ivanp@usal.es

Angélica González · Manuel Rubio · Javier Bajo

Departamento Informática y Automática

Universidad de Salamanca

Plaza de la Merced s/n, 37008, Salamanca, Spain

e-mail: \{angelica, mprc, jbajope\}@usal.es

E. Corchado et al. (Eds.): SOCO 2010, AISC 73, pp. 1-8. springerlink.com @ Springer-Verlag Berlin Heidelberg 2010 
enabling its use in real time. Additionally, the adaptation phase in the CBR system that is integrated in the agent proposes a new analysis classification model that is carried out by a mixture of experts. This new model makes it possible to divide the complicated classification task into a series of simple subtasks, so that the fusion of the solutions given by the sub tasks generates the final solution.

Our proposal can be considered as a solid alternative to detect and block DoS attacks. We continue working to achieve a full prototype and then evaluate it within several real environments to probe its effectiveness.

Acknowledgments. This work has been supported by the Spanish Ministry of Science and Innovation TIN 2009-13839-C03-03 and The P.E.P. 2006-2010 IFARHU-SENACYTPanama.

\section{References}

[1] Corchado, J.M., Laza, R., Borrajo, L., Yañez, J.C., Luis, A.D., Valiño, M.: Increasing the Autonomy of Deliberative Agents with a Case-Based Reasoning System. International Journal of Computational Intelligence and Applications 3, 101-118 (2003)

[2] Chonka, A., Zhou, W., Xiang, Y.: Defending Grid Web Services from XDoS Attacks by SOTA. In: IEEE International Conference on Pervasive Computing and Communications, pp. 1-6. IEEE Computer Society, Los Alamitos (2009)

[3] De Paz, J.F., Rodríguez, S., Bajo, J., Corchado, J.M.: Case-based reasoning as a decision support system for cancer diagnosis: A case study. International Journal of $\mathrm{Hybr}-$ id Intelligent Systems 6, 97-110 (2009)

[4] Dean, T., Boddy, M.S.: An Analysis of Time-Dependent Planning. In: 7th National Conference on Artificial Intelligence, pp. 49-54 (1988)

[5] Gruschka, N., Jensen, M., Luttenberger, N.: A Stateful Web Service Firewall for BPEL. In: IEEE International Conference on Web Services, pp. 142-149 (2007)

[6] Im, E.G., Song, Y.H.: An Adaptive Approach to Handle DoS Attack for Web Services. In: Heidelberg, S.B. (ed.) Intelligence and Security Informatics, pp. 634-635 (2005)

[7] Julian, V., Botti, V.: Developing real-time multi-agent systems. Integrated ComputerAided Engineering 11, 135-149 (2004)

[8] Padmanabhuni, S., Singh, V., Kumar, K.M.S., Chatterjee, A.: Preventing Service Oriented Denial of Service (PreSODoS): A Proposed Approach. In: IEEE International Conference on Web Services (ICWS 2006), pp. 577-584. IEEE Computer Society, Washington (2006)

[9] Ye, X.: Countering DDoS and XDoS Attacks against Web Services. In: IEEE/IFIP International Conference on Embedded and Ubiquitous Computing, pp. 346-352. IEEE Computer Society, Washington (2008)

[10] Yee, C.G., Shin, W.H., Rao, G.S.V.R.K.: An Adaptive Intrusion Detection and Prevention (ID/IP) Framework for Web Services. In: International Conference on Convergence Information Technology (ICCIT 2007), pp. 528-534. IEEE Computer Society, Washington (2007)

\section{Approaching Real- through MOVICAl}

Martí Navarro, Álvaro Herrero, En

\begin{abstract}
This paper presents an gent Intrusion Detection System c to enable real-time processing and CAB-IDS combines artificial neur multiagent system to perform Intru The contribution of the anytime al tificial Intelligent techniques to re sented in this work.
\end{abstract}

Keywords: Multiagent Systems, I Network Security, Intrusion Detec liberative Process.

\section{Introduction}

Softcomputing techniques and para Detection Systems (IDSs) [1]. M tionist Agent-Based IDS) has bee

Martí Navarro · Vicente Julián

Departamento de Sistemas Informático Universidad Politécnica de Valencia, C e-mail: \{mnavarro, vinglada\} ed

Álvaro Herrero

Civil Engineering Department, Univer C/ Francisco de Vitoria s/n, 09006 Bur e-mail: ahcosio@ubu.es

Emilio Corchado

Departamento de Informática y Autom Plaza de la Merced s/n 37008, Salaman e-mail: escorchado@usal.es

E. Corchado et al. (Eds.): SOCO 2010, A springerlink.com (C) Springer-Verlag Berli 
The series "Advances in Intelligent and Soft Computing" contains publications on various areas within so-called soft computing which include fuzzy sets, rough sets, neural networks, evolutionary computations, probabilistic and evidential reasoning, multi-valued logic, and related fields. The publications within "Advances in Intelligent and Soft Computing" are primarily textbooks and proceedings of important conferences, symposia and congresses. They cover significant recent developments in the field, both of a foundational and applicable character. An important characteristic feature of the series is the short publication time and world-wide distribution. This permits a rapid and broad dissemination of research results.

\section{Emilio Corchado - Paulo Novais - Cesar Analide - Javier Sedano (Fds)}

Soft Computing Models in Industrial and Environmental Applications. 5th International Workshop (SOCO) 2010)

This volume of Advances in Intelligent and Soft Computing contains accepted papers presented at SOCO 2010 held in the beautiful and historic city of Guimaràes, Portugal, June 2010. 'This volume presents the papers accepted for the 2010 edition, both for the main event and the Special Sessions. SOC() 2010 Special Sessions are a very useful tool in order to complement the regular program with new or emerging topics of particular interest to the participating community. Special Sessions that emphasize on multi-disciplinary and transversal aspects, as well as cutting-edge topics were specially encouraged and welcome.

ISSN $1867-5662$

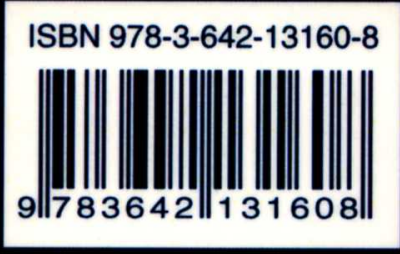

\section{Available online}

springer.com 